\title{
Phytoremediation of Heavy Metals Released from Mining Waste Drainage using Selected Plant Species, in Ethiopia
}

\begin{abstract}
Mehari Girmay*
Ethiopia

*Corresponding Author: Mehari Girmay, Ethiopia

Abstract: Mining is known in releasing of heavy metals and environmental pollutants due to their toxicity, persistence in the environment, and bio-accumulative nature. Leaching activity of mining has a major role in releasing of chemicals which toxify to the mining environment. Such activity contaminates the terrestrial ecosystems with toxic heavy metals that lead to the environmental problem of public health concern. In Ethiopia, even the mining trend is accounted long time, the environmental and social impacts are underestimated and not taken as an issue for a long time. However, these impacts are become very risky and problematic from time to time, since mining companies are not dedicated to their environmental and social impact assessment commitments.

Being persistent pollutants, heavy metals accumulate in the environment and consequently contaminate the food chains. Accumulation of potentially toxic heavy metals in biota causes a potential health threat to their consumers including humans. Phytoremediation is more cost-effective than alternative mechanical or chemical methods of removing hazardous compounds from the soil. Vetiver grass is a perennial grass belonging to the Poaceae family with short rhizomes and a massive, finely structured root system. The deep root system makes the vetiver grass extremely drought tolerant and very difficult to dislodge when exposed to strong water flow. The main purpose of this study is to review the ecological impacts of mining in releasing leached wastes/drainages/ and the possible and effective techniques of treatment via Phytoremediation technology.
\end{abstract}

Keywords: Ethiopia, Mining, Vertiver grass, Phytoremediation, leaching

\section{Mining IMPACTS ON ECOSYSTEM}

Tailings arise where mined ores are upgraded to concentrates or final products by physical processes such as screening, crushing and grinding or by chemical methods such as leaching. The waste material or tailings may be disposed of in a number of ways. Land-based storage is the most common method used. It usually involves constructing a dam across a valley and creating a tailings impoundment, except in flat areas where the 'dam' may encircle the entire impoundment. In some circumstances, it may be possible to return tailings to a mined void (ICMM, 2006). Since most of the mining byproduct is in liquefied and semi-liquid sated, there will a high tendency to peculating and leakage to nearby situated water bodies. Such mining mechanisms can lead to different problems such as polluting the soil, water, and air of the mining sites, recycling of hazardous metals/chemicals through the food chain, falling adjacent residences to different health risks. Such problems are more common in the miners who have poor/weak tailing dam assessment and management methods (ICMM, 2006).

According to Mehari (2018), Deforestation, Siltation, Formation of trench and pits, topsoil removal, Water pollution, Veldt fires, Land degradation and chemical releasing are the major impacts mining executed in Ethiopia. Furthermore, he states that both Artisanal and large scale miners are widely used different chemicals as the recovery of the desired mineral from its ore. However, chemical utilization by the miners is implemented with any consideration of its ecological impacts. As a result, the huge potential of heavy metal is released and accumulated from the mine waste and mine water.

\section{What are the Toxic Heavy Metals Released from Mine Drainage Frequently?}

The most common heavy metal contaminants are $\mathrm{Cd}, \mathrm{Cr}, \mathrm{Cu}, \mathrm{Hg}, \mathrm{Pb}$, and $\mathrm{Zn}$. Metals are natural components in soil. Some of these metals are micronutrients necessary for plant growth, such as $\mathrm{Zn}$, $\mathrm{Cu}, \mathrm{Mn}, \mathrm{Ni}$, and $\mathrm{Co}$, while others have an unknown biological function, such as $\mathrm{Cd}, \mathrm{Pb}$, and $\mathrm{Hg}$ (Gaur 
A. and Adholeya A., 2004). Mining in its nature leads a generation of large quantities of heavy metalladen wastes since it passes through cyanide process, acid mining solution or else methods with high tendency to release mine waste drainage. Subsequently, this causes widespread contamination of an ecosystem (Lasat M., 2000). According to Mehta et.al, (2005) the most common of heavy metals and their future is described here below:

- Mercury (Hg): is a shiny, silver-white, odorless liquid. Mostly found with other elements, such as chlorine, sulfur, or oxygen, to form inorganic mercury compounds or salts, which are usually white powders or crystals. Mercury is a persistent environmental pollutant with bioaccumulation ability in fish, animals, and human beings. However, Mercury has a high recovery potential to extract gold and other metalloids from their ore. That's why most the miners are using this chemical commonly, even it is illegal in accordance with Mina Mata regulation which is adopted and sign to ban it from any use by Ethiopia.

- Arsenic (As). Arsenic is one of the contaminants found in the environment which is notoriously toxic to man and other living organisms. It is a highly toxic element that exists in various species, and the toxicity of arsenic depends on its species.

- Lead $(\mathbf{P b})$. Soil can be contaminated with $\mathrm{Pb}$ from several other sources such as industrial sites, from leaded fuels, old lead plumbing pipes, or even old orchard sites in production where lead arsenate is used. Lead accumulates in the upper 8 inches of the soil and is highly immobile. Contamination is long-term. Without remedial action, high soil lead levels will never return to normal. In the environment, lead is known to be toxic to plants, animals, and microorganisms. $\mathrm{Pb}$ contamination in the environment exists as an insoluble form, and the toxic metals pose a serious human health problem, namely, brain damage and retardation.

\section{Biological Methods of Mine Waste Drainage Treatment (Phytoremediation METHOD)}

Metal pollution has a harmful effect on biological systems and does not undergo biodegradation. Toxic heavy metals such as $\mathrm{Pb}, \mathrm{Co}, \mathrm{Cd}$ can be differentiated from other pollutants since they cannot be biodegraded but can be accumulated in living organisms, thus causing various diseases and disorders even in relatively lower concentrations. Heavy metals, with soil residence times of thousands of years, pose numerous health dangers to higher organisms. They are also known to have an effect on plant growth, ground cover and have a negative impact on soil microflora. It is well known that heavy metals cannot be chemically degraded and need to be physically removed or be transformed into nontoxic compounds (Roy et.al, 2005).

Many species of plants have been successful in absorbing contaminants such as lead, cadmium, chromium, arsenic, and various radionuclides from soils. One of the phytoremediation categories, phytoextraction, can be used to remove heavy metals from soil using its ability to uptake metals which are essential for plant growth $(\mathrm{Fe}, \mathrm{Mn}, \mathrm{Zn}, \mathrm{Cu}, \mathrm{Mg}, \mathrm{Mo}$, and $\mathrm{Ni}$ ). Some metals with unknown biological function (Cd, Cr, Pb, Co, Ag, Se, Hg) can also be accumulated (Lasat M., 2000).

Biological method of waste drainage treatment is more feasible and preferable because it can be applied without using any chemical, with no impact on mining ecosystem (environmentally friendly) and potentially cost-effective. Many species of plants have been successful in absorbing contaminants such as lead, cadmium, chromium, arsenic, and various radionuclides from soils which are essential for plant growth. It is well known that heavy metals cannot be chemically degraded and need to be physically removed or be transformed into nontoxic compounds (Roy et.al, 2005).

Because of its good quality of ecological adaptability and resistance to various environmental impacts, Vetiver grass (Cymbopogon citratus/sometimes also called Vetiveria zizanioides) is more preferable and efficient in up taking and translocation of to the most common heavy metals released from mine waste drainages such $\mathrm{Co}, \mathrm{Zn}, \mathrm{Cd}, \mathrm{Pb}, \mathrm{Ni}$, and as from roots to shoot. Cymbopogon citratus is perennial and has the capability to adapt in dry, rocky and chemically contaminated areas. Mining in Ethiopia is commonly executed in dry ago-ecology where most it is rocky and water scarce. That's why such plant species are more compatible in Ethiopian mining areas to uptake heavy metals from mine waste and mine drainages. 
Phytoremediation of Heavy Metals Released from Mining Waste Drainage using Selected Plant Species, in Ethiopia

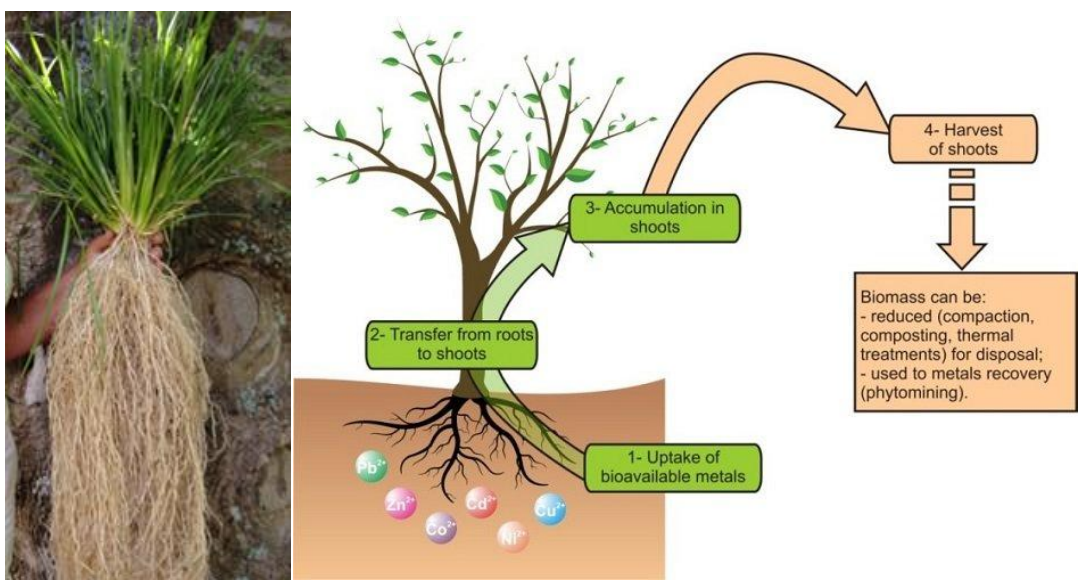

Figure1. Divulges how Vetiver grass (Cymbopogon citratus) treats heavy metals contamination

\section{The General Outcome of Phytoremediation}

Heavy metals uptake, by plants (phytoremediation), seems to be a comfortable way to remediate heavy metals contaminated environment. In Ethiopia mining has various impacts on both environment and human health. If the mining company uses such biological treatment to minimize ecological risks, it will bring the following outcomes:(A) less toxicity of the soil, water or other ecosystem components at/around the mining sites, (B)stabilized and reduced magnitude of heavy metals $(\mathrm{Co}, \mathrm{Zn}, \mathrm{Cd}, \mathrm{Pb}, \mathrm{Ni}$, and As) concentration, $\mathrm{PH}$ and other chemicals associated with the mine waste drainage, (C) creating healthy \& impact free livelihood (both human \& animal) in/around the mining areas and (D) finally clean and green area (because it is done via floral plantation) as well sustainable and environmentally friendly mining developments.

In most mining activities, including in Ethiopia, mining waste treatment is conducted either by using a chemical method or by retention/exposing the waste to the environment naturally (especially for cyanide and heavy metals). However, methods such this in this project will have multi-purpose advantages, easy and cost-effective methods which require adopting it to treat Heavy metals released either from mining waste or other developmental activities.

\section{REFERENCES}

[1] Environmental Impact Assessment Guideline For Mineral and Petroleum Operation Projects, 2003.

[2] ICMM., (International Council on Mining and Metals), 2006. Good Practice Guidance for Mining and Biodiversity International Council on Mining and Metals (ICMM), London, UK

[3] Gaur A., Adholeya A., 2004. "Prospects of arbuscular mycorrhizal fungi in phytoremediation of heavy metal contaminated soils," Current Science, vol. 86, no. 4, pp. 528-534.

[4] Lasat M., 2000. "Phytoextraction of metals from contaminated soil: a review of plant/soil/metal interaction and assessment of pertinent agronomic issues," Journal of Hazardous Substance Research, vol. 2, no. 5, pp. 1-25.

[5] Mehari G., (2018)" Assessment for Artisanal Gold Mining Impacts on Vegetation Ecology at Shire Districts, Tigray-Ethiopia", Southeast Cameroon, International Journal of Mining Science (IJMS), 4(4), pp.38-43, DOI: http://dx.doi.org/10.20431/2454-9460.0404004.

[6] Mehta, P., Roy, S., Labelle S., 2005., "Phytoremediation of heavy metal and PAH-contaminated brownfield sites," Plant and Soil, vol. 272, no. 1-2, pp. 277-290.

[7] Roy S., Labelle S., Mehta P., 2005 ."Phytoremediation of heavy metal and PAH-contaminated brownfield sites," Plant and Soil, vol. 272, no. 1-2, pp. 277-290.

Citation: Mehari Girmay, (2019)" Phytoremediation of Heavy Metals Released from Mining Waste Drainage using Selected Plant Species, in Ethiopia”, Southeast Cameroon, International Journal of Mining Science (IJMS), 5(3), pp.11-13, DOI: http://dx.doi.org/10.20431/2454-9460.0503002

Copyright: (0) 2019 Authors. This is an open-access article distributed under the terms of the Creative Commons Attribution License, which permits unrestricted use, distribution, and reproduction in any medium, provided the original author and source are credited 